\title{
Orion ECLSS/Suit System - Ambient Pressure Integrated
} Suit Test

\begin{abstract}
Richard A. Barido ${ }^{1}$
The Ambient Pressure Integrated Suit Test (APIST) phase of the integrated system testing of the Orion Vehicle Atmosphere Revitalization System (ARS) technology was conducted for the Multipurpose Crew Vehicle (MPCV) Program within the National Aeronautics and Space Administration (NASA) Exploration Systems Mission Directorate. This test was performed in the eleven-foot human-rated vacuum chamber at the NASA Johnson Space Center by the Crew and Thermal Systems Division. This testing is the first phase of suit loop testing to demonstrate the viability of the Environmental Control and Life Support System (ECLSS) being developed for Orion. APIST is the first in a series, which will consist of testing development hardware including the CAMRAS, air revitalization loop fan with human test subjects in pressure suits at varying suit pressures. Follow-on testing, to be conducted in 2012, will utilize the CAMRAS and a development regulator with human test subjects in pressure suits at varying cabin and suit pressures. This paper will discuss the results and findings of APIST and will also discuss future testing.
\end{abstract}

${ }^{1}$ Orion ECLS Subsystem Manager for Air Revitalization and Suit Loop Systems, 2101 NASA Parkway, Mail Stop: EC6. 